\title{
Findings from an online behavioural weight management programme provided with or without a fortified diet beverage
}

\author{
C. Keith Haddock ${ }^{1}$, Walker S. C. Poston ${ }^{1 *}$, Caitlin LaGrotte ${ }^{2}$, Alicia A. Klotz ${ }^{2}$, Tracy L. Oliver ${ }^{2}$, \\ Stephanie S. Vander Veur ${ }^{2}$, Gary D. Foster ${ }^{2}$, Susan A. Jebb ${ }^{3}$, Carmel Moore ${ }^{3}$, Susan A. Roberts ${ }^{4}$, \\ Rebecca S. Reeves ${ }^{5}$, Mary Pat Bolton ${ }^{5}$ and John P. Foreyt ${ }^{5}$ \\ ${ }^{1}$ Institute for Biobehavioral Health Research, National Development and Research Institutes, Inc., \\ 1920 West 143rd Street, Suite 120, Leawood, KS 66224, USA \\ ${ }^{2}$ Temple University, Philadelphia, PA, USA \\ ${ }^{3}$ MRC Human Nutrition Research, Elsie Widdowson Laboratory, Cambridge, UK \\ ${ }^{4}$ Global Scientific and Regulatory Affairs, The Coca-Cola Company, Atlanta, GA, USA \\ ${ }^{5}$ Behavioral Medicine Research Center, Baylor College of Medicine, Houston, TX, USA
}

(Submitted 5 February 2013 - Final revision received 24 June 2013 - Accepted 24 June 2013 - First published online 7 August 2013)

\begin{abstract}
The present multi-centre randomised weight-loss trial evaluated the efficacy of a low-intensity 12-week online behavioural modification programme, with or without a fortified diet beverage using a $2 \times 2$ factorial design. A total of 572 participants were randomised to: (1) an online basic lifestyle information (OBLI) intervention, consisting of one online informational class about tips for weight management; (2) an online behavioural weight management (OBWM) intervention, entailing 12 weekly online classes focused on weight-loss behaviour modification; (3) an OBLI intervention plus a fortified diet cola beverage (BEV) containing green tea extract (total catechin $167 \mathrm{mg}$ ), soluble fibre dextrin (10 g) and caffeine (100 mg) (OBLI + BEV); (4) OBWM + BEV. Assessments included height, weight, dual-energy X-ray absorptiometry-derived body composition, and waist circumference (WC). Attrition was $15 \cdot 7 \%$. Intention-to-treat (ITT) models demonstrated a main effect for type of Internet programme, with those assigned to the OBWM condition losing significantly more weight $(F=7 \cdot 174 ; P=0.008)$ and fat mass $(F=4.491 ; P=0.035)$ than those assigned to the OBLI condition. However, there was no significant main effect for the OBWM condition on body fat percentage $(F=2 \cdot 906 ; P=0.089)$ or WC $(F=3 \cdot 351 ; P=0 \cdot 068)$, and no significant main effect for beverage use or significant interactions between factors in ITT models. A 12-week, low-intensity behaviourally based online programme produced a greater weight loss than a basic information website. The addition of a fortified diet beverage had no additional impact.
\end{abstract}

Key words: Weight loss: Obesity: Internet: Online behavioural modification programmes

The global prevalence of overweight and obesity is a major public health concern, with particularly high rates in the USA and the European Union $^{(1)}$. More than two-thirds (68.0\%, 95\% CI 66.3, 66.9) of adult Americans are overweight or obese ${ }^{(2)}$. Greater than half of the adults in the European Union are overweight or obese, and the rate of obesity (15.5\% across all European Union countries) has more than doubled in the past 20 years $^{(3)}$. Testing approaches to weight loss that are potentially effective and can be widely disseminated is a global public health priority.

Online weight-loss programmes have been studied in an attempt to provide a cost-effective and scalable approach to delivering behavioural modification treatment for obesity ${ }^{(4-13)}$.
A recent review of these programmes has demonstrated weight losses ranging from 1.3 to $7.6 \mathrm{~kg}$ for completers and 0.8 to $4.9 \mathrm{~kg}$ for intention-to-treat (ITT) populations ${ }^{(14)}$. While the overall change across studies was not computed due to variations in intervention methods and time, the authors have noted that weak adherence to treatment and attrition were common problems and that tailored materials and self-reporting improved retention and outcomes ${ }^{(14)}$. Other investigators have noted that key features of successful Internet interventions included structured lesson plans, 'calorie'-counting, daily record-keeping and submission, feedback and reinforcement, interactivity, accessibility (home Internet that can be accessed $24 \mathrm{~h} / \mathrm{d}$ ) and anonymity $^{(8)}$.

Abbreviations: BEV, fortified diet beverage; ITT, intention to treat; OBLI, online basic lifestyle information; OBWM, online behavioural weight management. 
In addition to behavioural modification approaches to support weight loss, various food ingredients have been investigated for potential benefits in weight management ${ }^{(15,16)}$. For example, tea extract with caffeine has been shown to increase total energy expenditure and fat oxidation ${ }^{(17-19)}$ and to have a positive impact on body weight, fat mass, visceral fat and blood biomarkers of metabolic risk ${ }^{(15,16,20-23)}$.

Dietary fibre has been associated with a reduced risk of weight gain in prospective epidemiological studies ${ }^{(24)}$, while clinical trials have shown mixed results ${ }^{(25)}$. However, soluble fibre dextrin may have a weight-loss benefit, as it has been shown to prevent weight gain over a 5 -week period ${ }^{(26)}$ and promoted weight loss and satiety in a 12 -week trial ${ }^{(27,28)}$.

To increase the potential for scalability, the current programme applied behavioural modification concepts with low-touch support. A low-energy, diet cola beverage fortified with green tea extract, soluble fibre dextrin, and caffeine was added as a simple means to deliver additional weight management benefits. The present study investigated the impact of an innovative combination of a fortified diet beverage in conjunction with an online weight-loss programme in a multi-centre randomised clinical trial. The study compared the impact of four combinations of the beverage and the online behavioural modification treatment programme (i.e. a $2 \times 2$ factorial design of online weekly treatment $v$. online basic lifestyle information (OBLI) and fortified beverage $v$. no beverage) on weight and body composition over 12 weeks at three treatment centres in the USA ( $n$ 2) and European Union $(n 1)$.

\section{Methods}

\section{Study design overview}

The present 12-week randomised trial used a 2 (online behavioural weight management (OBWM) $v$. OBLI intervention) $\times 2$ (fortified beverage $v$. none) factorial design that resulted in four intervention groups. The study was conducted at two US (Houston and Philadelphia) and one UK (Cambridge) sites. The Institute for Biobehavioral Health Research at the National Development and Research Institutes served as the data analytic centre. The present study was conducted according to the guidelines laid down in the Declaration of Helsinki, and all procedures involving human subjects/patients were approved by the Baylor College of Medicine Institutional Review Board, the Western Institutional Review Board and the Cambridgeshire 3 Research Ethics Committee. Written informed consent was obtained from all the participants. The present trial has been registered at Clinical Trials (no. NCTO1492413).

\section{Participants and procedures}

Participants were recruited for the present study through databases of research participants, via local advertisements and by inquiry at the clinic or word of mouth. The applicants were screened by phone and in person to confirm eligibility before the start of the study. Inclusion criteria for participation in the study included: (1) interest in participating in a weight-loss study; (2) BMI of $25-40 \mathrm{~kg} / \mathrm{m}^{2}$; (3) age $18-65$ years; (4) systolic blood pressure $<140 \mathrm{mmHg}$ and diastolic blood pressure $<90 \mathrm{mmHg}$; (5) caffeine intake $100-400 \mathrm{mg} / \mathrm{d}$; (6) ability to participate in physical activity for a minimum of $150 \mathrm{~min} /$ week; (7) having Internet access and feeling comfortable navigating within a website and entering data online. In addition, all prospective participants were given a glass of the fortified beverage and the opportunity to determine whether they felt they could consume the required amount each day for the duration of the study.

Exclusion criteria included: (1) inability to consume the required amount of beverage each day; (2) inability to access or use the Internet at the level required for the intervention; (3) pregnancy, lactation or actively trying to become pregnant; (4) medical illnesses or medications that could affect body weight; (5) smokers; (6) weight loss of 10 or more pounds ( 4.5 or more $\mathrm{kg}$ ) in the last 3 months; (7) fasting blood glucose $>1260 \mathrm{mg} / \mathrm{l}$; (8) participation in a clinical research study that would conflict with the purpose of the present trial; (9) other factors that in the judgement of the principal investigators may interfere with study participation or the ability to follow the intervention protocol. Participants meeting the inclusion criteria were randomised to one of the four treatment conditions. All participants gave written informed consent before enrolling in the study.

\section{Treatment conditions}

Participants were randomly assigned to one of the four treatment conditions, described in detail below. All the four treatments had the same prescribed energy intake that was based on the Mifflin-St Jeor equation for estimating resting energy expenditure ${ }^{(29)}$, resulting in a deficit of $2092 \mathrm{~kJ} / \mathrm{d}$ $(500 \mathrm{kcal} / \mathrm{d})$ (thus keeping the intake between 5021 and $7531 \mathrm{~kJ} / \mathrm{d}(1200$ and $1800 \mathrm{kcal} / \mathrm{d}))$ with $\leq 30 \%$ of energy from fat to induce weight loss. Participants in all the four groups were encouraged to include at least $150 \mathrm{~min} /$ week of moderate or vigorous physical activity. Finally, all participants were asked to keep a food diary on a daily basis for the first 2 weeks of the study and then three times per week for the remainder of the trial as a method of behavioural self-monitoring.

\section{Online basic lifestyle information}

This condition consisted of basic lifestyle information presented on a static website, which included information on behavioural strategies to modify diet and physical activity for weight management. Following the conclusion of the 12-week programme, participants in the OBLI group were given a 1-month supply of the fortified diet beverage.

\section{Online behavioural weight management}

In an OBWM programme, twelve weekly lifestyle lessons that included nutrition, physical activity and behaviour modification were provided.

All topics in the Internet programme were accompanied by assignments. As noted previously, participants were asked to 
record their food intake daily for the first 2 weeks and then three times per week for the remainder of the study. As a means to provide feedback to participants, once a goal was met, a check mark on the home page automatically appeared, indicating that the specific activity had been completed. These targeted activities included: recording energy intake and visits to the website; completing food diaries, activity logs, beverage logs and lesson plans; tracking weight; using the online support community. A dashboard was included on the intervention homepage that tracked the participants' entries. Following the conclusion of the 12-week programme, the participants in the OBWM group were given a 1-month supply of the fortified diet beverage.

Online tools were available to track food intake, weight and physical activity. The participants could also participate in chat room forums on the intervention website for communication and support.

Online basic lifestyle information + fortified diet beverage. Participants randomised to this group received the OBLI condition as described above and three cans per $\mathrm{d}$ of the fortified diet cola beverage. Each beverage was a $12 \mathrm{oz}(355 \mathrm{ml})$ diet cola beverage fortified with $83 \mathrm{mg}$ of green tea extract containing $83 \mathrm{mg}$ of epigallocatechin gallate (total catechin $167 \mathrm{mg}$ ), $10 \mathrm{~g}$ of soluble fibre dextrin and $100 \mathrm{mg}$ caffeine. The fibre contained $8 \mathrm{~kJ} / \mathrm{g}$ ( $2 \mathrm{kcal} / \mathrm{g}$ ), so each beverage provided $83 \mathrm{~kJ}$ ( $20 \mathrm{kcal})$ of energy. Participants were instructed to drink three cans of the beverage per $d$ and access the website regularly to log beverage usage, but no additional weight management advice was provided.

Online behavioural weight management + fortified diet beverage. Participants randomised to this condition received the OBWM and BEV intervention components described above.

\section{Measurement}

Measurement overview. The measurements described below were conducted at baseline, 6 and 12 weeks.

Height, weight, BMI and waist circumference. Height was assessed once, within $1 \mathrm{~cm}$ using a stadiometer. Body weight was determined once to the nearest $0 \cdot 1 \mathrm{~kg}$ using a calibrated scale. Waist circumference was determined to the nearest $0.5 \mathrm{~cm}$ using a spring-loaded, non-stretchable tape measured around the abdomen horizontally at the midpoint between the highest point of the iliac crest and the lowest part of the costal margin in the mid-axillary line.

Fat mass and body fat percentage. Fat mass (kg) and body fat percentage were determined by dual-energy X-ray absorptiometry using a whole-body scan.

Blood pressure. Blood pressure cuff size was based on the participants' measured arm circumference. Blood pressure was assessed after the participant was seated quietly for 5 min with the cuff in place. Thereafter, two measures were taken, separated by $2 \mathrm{~min}$, and averaged to obtain each participant's blood pressure.

\section{Data analysis}

Sample size. The study was powered to examine changes in weight $(\mathrm{kg})$ and dual-energy X-ray absorptiometry-derived fat mass (kg), and based on statistical parameters supplied by Hunter et $a l .{ }^{(12)}$, Nagao et al. ${ }^{(30)}$ and Pritchard et $a l .{ }^{(31)}$. The power analyses of the present study assumed random assignment, roughly equal number of women in each group, baseline weight as a covariate, up to $20 \%$ attrition and nominal levels of $\alpha(0.05)$ and power (0.80). Thus, randomising at least 500 participants across the four treatment conditions would provide adequate power to detect a minimum difference of $1.0 \mathrm{~kg}$ between any of the treatment groups for the primary contrasts and post hoc analyses. A $1.0 \mathrm{~kg}$ difference was the smallest post hoc difference hypothesised in the present study (i.e. for the comparison between the OBLI $v$. OBLI + BEV intervention).

Statistical plan. Consistent with the 2 (OBWM $v$. OBLI intervention) $\times 2$ (fortified beverage $v$. none) factorial design, we examined the main effects for each factor and potential interactions between factors by examining changes in primary body composition outcomes between groups from baseline to 12 weeks (end of the treatment) using an ITT model and a 'completers' analysis. ITT models were based on the baselineobservation-carried-forward approach ${ }^{(4,32-34)}$. We conducted completers and baseline-observation-carried-forward models for 12 -week changes in weight, fat mass and waist circumference (Table 2). One-way ANCOVA models were used to evaluate weight differences because they are easier to interpret in a clinical context, using the relevant baseline body composition variable as a covariate.

\section{Primary study hypotheses}

The three primary hypotheses were: (1) after 12 weeks, individuals in the OBWM conditions would lose more weight than those in the OBLI conditions (main effect for factor 1); (2) after 12 weeks, individuals in the OBWM $+\mathrm{BEV}$ and OBLI + BEV conditions would lose more weight than those not receiving the fortified beverage (main effect for factor 2); (3) after 12 weeks, individuals in the OBLM + BEV condition would lose more weight than those in the other groups (interactions between factors 1 and 2).

\section{Results}

\section{Description of participants}

A total of 572 participants were randomised to one of the four treatment conditions. Fig. 1 illustrates the study design and flow of the participants. Table 1 presents the characteristics of the participants at baseline by group of assignment.

There were no significant differences between the intervention groups in the distribution of any of the baseline demographic or clinical variables. As can be seen in Table 1, the study participants were primarily Caucasian women in their mid-forties who were college educated or higher, married or living with a partner and employed full time. Participants in all the groups had an average BMI more than $30 \mathrm{~kg} / \mathrm{m}^{2}$ and an average body fat percentage more than $40 \%$.

\section{Attrition}

In the 12 -week trial, attrition was $15 \cdot 7 \%$ (ninety of 572 participants; Fig. 1). Dropout was statistically significant among the

mass (kg), and based on statistical parameters supplied 
treatment conditions $\left(\chi^{2}=12.090 ; \quad P=0 \cdot 007\right)$. Participants assigned to the OBWM (OR 3.628; $P=0.001)$ or OBWM + BEV (OR 2.545; $P=0.019$ ) condition were significantly more likely to drop out than those assigned to the OBLI condition. In addition, participants who were older (OR 0.977; $P=0.045$ ) and college graduates (OR $0.465 ; P=0.003$ ) were significantly less likely to drop out than those who did not graduate from college/university. Finally, participants were more than three times as likely to drop out at the UK study site (Medical Research Council (MRC): OR 3.198; $P=0.003$ ) when compared with the referent site (Baylor College of Medicine; BCM), while dropouts for the BCM and Temple University (TU) study sites were not significantly different.

\section{Changes in weight, fat mass and waist circumference}

Table 2 provides baseline to 12-week weight change data for the primary outcomes for all the four groups.

Consistent with hypothesis 1 , there was a main effect for type of Internet programme for the ITT models, with those assigned to the OBWM condition losing significantly more weight $(F=7 \cdot 174 ; \quad P=0.008)$ and fat mass $(F=4.491$; $P=0.035)$ than those assigned to the OBLI condition. However, there was no significant main effect for the OBWM condition on body fat percentage $(F=2.906 ; P=0.089)$ or waist circumference $(F=3.351 ; P=0.068)$. None of the ITT models for the primary outcomes demonstrated main effects

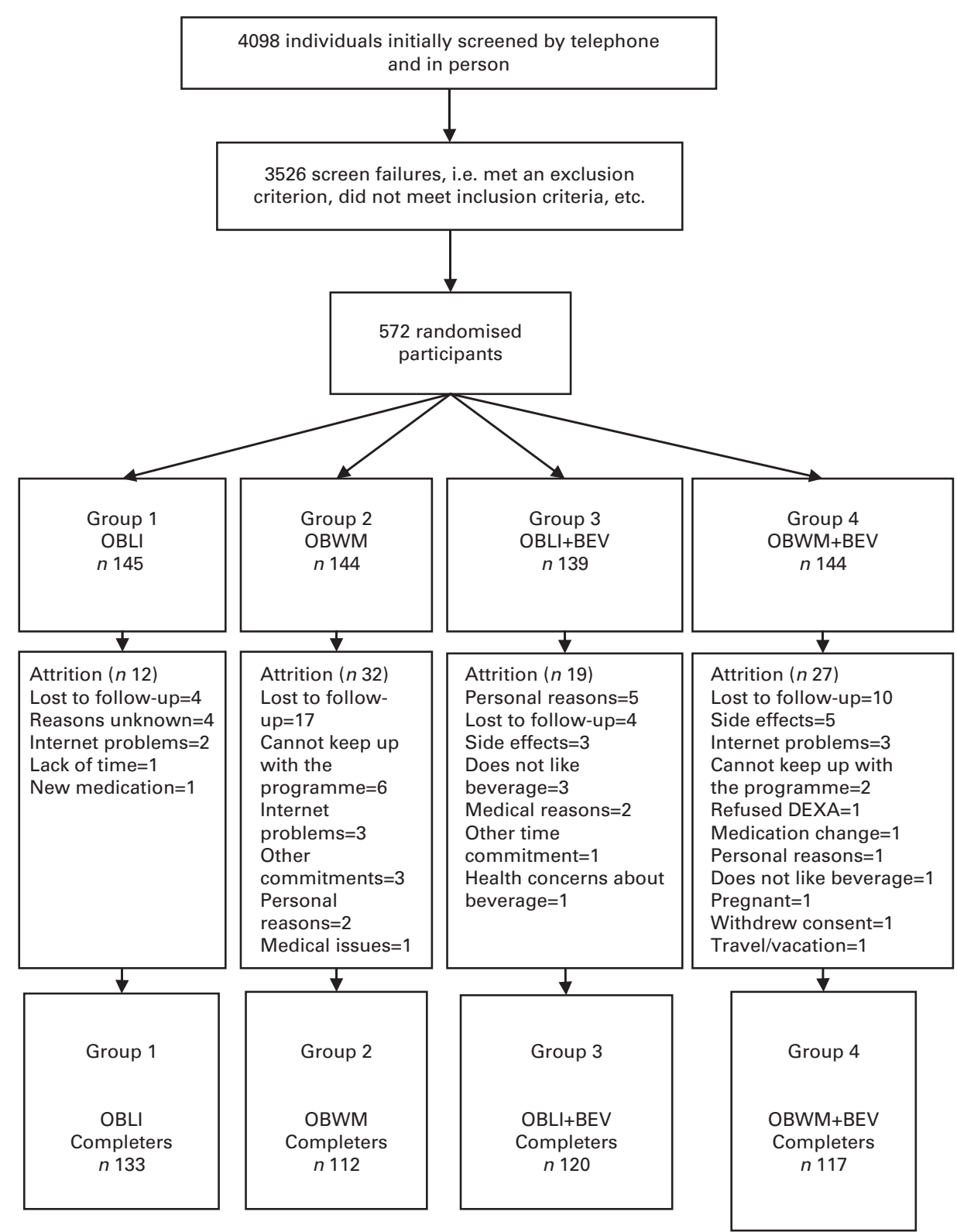

Fig. 1. Randomisation of the eligible participants. OBLI, online basic lifestyle information; OBWM, online behavioural weight management; BEV, fortified diet beverage; DEXA, dual-energy X-ray absorptiometry. 
Table 1. Baseline characteristics of the participants by group of assignment ${ }^{\star}$ (Mean values and standard deviations; percentages)

\begin{tabular}{|c|c|c|c|c|c|c|c|c|}
\hline & \multicolumn{8}{|c|}{ Group of assignment } \\
\hline & \multicolumn{2}{|c|}{ OBLI } & \multicolumn{2}{|c|}{ OBWM } & \multicolumn{2}{|c|}{ OBLI + BEV } & \multicolumn{2}{|c|}{ OBWM + BEV } \\
\hline & Mean & SD & Mean & SD & Mean & SD & Mean & SD \\
\hline Baseline $(n)$ & \multicolumn{2}{|c|}{145} & \multicolumn{2}{|c|}{144} & \multicolumn{2}{|c|}{139} & \multicolumn{2}{|c|}{144} \\
\hline Age (years) & $45 \cdot 3$ & 9.9 & $43 \cdot 8$ & $11 \cdot 8$ & $44 \cdot 6$ & $10 \cdot 6$ & $44 \cdot 3$ & $12 \cdot 0$ \\
\hline Weight (kg) & $88 \cdot 8$ & $13 \cdot 9$ & 88.5 & $12 \cdot 7$ & $89 \cdot 3$ & 14.4 & 89.7 & 13.4 \\
\hline BMI $\left(\mathrm{kg} / \mathrm{m}^{2}\right)$ & $32 \cdot 0$ & 3.7 & $32 \cdot 1$ & 3.6 & $32 \cdot 2$ & $3 \cdot 8$ & $32 \cdot 1$ & 3.5 \\
\hline Waist circumference (cm) & $102 \cdot 5$ & $11 \cdot 0$ & $102 \cdot 6$ & $10 \cdot 4$ & $102 \cdot 4$ & $11 \cdot 1$ & $102 \cdot 4$ & $10 \cdot 9$ \\
\hline DEXA total fat mass $(\mathrm{kg})$ & $35 \cdot 6$ & 7.5 & $35 \cdot 5$ & $7 \cdot 3$ & $36 \cdot 1$ & $8 \cdot 2$ & $35 \cdot 9$ & $8 \cdot 3$ \\
\hline DEXA body fat percentage & $40 \cdot 4$ & $5 \cdot 7$ & $40 \cdot 3$ & $6 \cdot 1$ & $40 \cdot 6$ & $6 \cdot 4$ & $40 \cdot 2$ & 6.5 \\
\hline Energy expenditure (kJ/d) & 7319.9 & 7911.9 & $7496 \cdot 9$ & 6878.5 & $6814 \cdot 1$ & $5750 \cdot 1$ & 6973.1 & $6307 \cdot 8$ \\
\hline Energy expenditure $(\mathrm{kcal} / \mathrm{d})$ & 1749.5 & $1891 \cdot 0$ & $1791 \cdot 8$ & $1644 \cdot 0$ & $1628 \cdot 6$ & $1374 \cdot 3$ & $1666 \cdot 6$ & $1507 \cdot 6$ \\
\hline Female (\%) & \multicolumn{2}{|c|}{$82 \cdot 8$} & \multicolumn{2}{|c|}{$82 \cdot 6$} & \multicolumn{2}{|c|}{$79 \cdot 9$} & \multicolumn{2}{|c|}{81.3} \\
\hline Married or living with a partner (\%) & \multicolumn{2}{|c|}{63.4} & \multicolumn{2}{|c|}{$63 \cdot 2$} & \multicolumn{2}{|c|}{$56 \cdot 8$} & \multicolumn{2}{|c|}{$63 \cdot 2$} \\
\hline Caucasian (\%) & \multicolumn{2}{|c|}{$60 \cdot 7$} & \multirow{2}{*}{\multicolumn{2}{|c|}{$\begin{array}{l}61.8 \\
63.9\end{array}$}} & \multicolumn{2}{|c|}{$63 \cdot 3$} & \multicolumn{2}{|c|}{62.5} \\
\hline College graduate or higher (\%) & \multicolumn{2}{|c|}{$\begin{array}{l}65 \cdot 5 \\
70 \cdot 3\end{array}$} & & & \multicolumn{2}{|c|}{$61 \cdot 9$} & \multicolumn{2}{|c|}{$60 \cdot 4$} \\
\hline Employed, paid, full-time (\%) & \multirow{2}{*}{\multicolumn{2}{|c|}{$\begin{array}{l}70 \cdot 3 \\
67 \cdot 6\end{array}$}} & \multicolumn{2}{|c|}{$63 \cdot 2$} & \multirow{2}{*}{\multicolumn{2}{|c|}{$\begin{array}{l}65 \cdot 5 \\
67 \cdot 6\end{array}$}} & \multirow{2}{*}{\multicolumn{2}{|c|}{$\begin{array}{l}63 \cdot 9 \\
68 \cdot 8\end{array}$}} \\
\hline Obese $\left(\mathrm{BMI} \geq 30 \mathrm{~kg} / \mathrm{m}^{2}\right)(\%)$ & & & \multicolumn{2}{|c|}{$67 \cdot 4$} & & & & \\
\hline
\end{tabular}

OBLI, online basic lifestyle information; OBWM, online behavioural weight management; BEV, fortified diet beverage; DEXA, dual-energy X-ray absorptiometry.

${ }^{*}$ Mean values were not significantly different between the groups for any of the baseline variables.

for the beverage factor or interactions, so hypotheses 2 and 3 were not supported.

Among completers, there were significant main effects for the OBWM condition on all primary outcomes, e.g. changes in weight $(F=10.674 ; \quad P=0.001)$, fat mass $(F=7.231$; $P=0.007)$, body fat percentage $(F=4.775 ; P=0.029)$ and waist circumference $(F=6 \cdot 161 ; P=0 \cdot 013)$. As with the ITT models, there were no significant main effects for factor 2 (fortified beverage) or interactions between the online programmes and beverage use, thus not supporting hypotheses 2 and 3 .

Because there was a significant main effect for the OBWM programme in the ITT models, we examined weight and fat mass loss by website use among those in the OBWM condition, using data from completers because only they can provide the actual data on website use. We categorised website use in the following manner: (1) less than weekly website logins or fewer than twelve logins during the 12-week study ( $n$ 22); (2) website logins averaging at least once per week, but less than several times per week (equal to or more than twelve logins, but less than thirty-six logins during the study; $n$ 78); (3) website logins averaging several times per week or more (equal to or more than thirty-six logins during the study; $n$ 129). We used this method of categorisation because participants in the OBWM groups were asked to use the website at least daily, and the other delineations were based on the

Table 2. Changes in primary study outcomes at 12 weeks by group of assignment

(Mean values and standard deviations)

\begin{tabular}{|c|c|c|c|c|c|c|c|c|}
\hline & \multicolumn{8}{|c|}{ Group of assignment } \\
\hline & \multicolumn{2}{|c|}{ OBLI } & \multicolumn{2}{|c|}{ OBWM } & \multicolumn{2}{|c|}{$\mathrm{OBLI}+\mathrm{BEV}$} & \multicolumn{2}{|c|}{$\mathrm{OBWM}+\mathrm{BEV}$} \\
\hline & Mean & $\overline{S D}$ & Mean & $\overline{\mathrm{SD}}$ & Mean & $\overline{S D}$ & Mean & $\overline{S D}$ \\
\hline \multicolumn{9}{|l|}{ BOCF $^{*}$} \\
\hline$n$ & \multicolumn{2}{|c|}{145} & \multicolumn{2}{|c|}{144} & \multicolumn{2}{|c|}{139} & \multicolumn{2}{|c|}{144} \\
\hline Weight (kg) & -0.7 & $2 \cdot 7$ & -1.4 & 2.9 & -1.0 & $2 \cdot 6$ & -1.5 & 3.1 \\
\hline BMI change $\left(\mathrm{kg} / \mathrm{m}^{2}\right)$ & -0.3 & 0.9 & -0.5 & 1.0 & -0.3 & 0.9 & -0.6 & 1.1 \\
\hline Waist circumference $(\mathrm{cm})$ & $-1 \cdot 2$ & 3.6 & $-2 \cdot 1$ & 3.6 & -1.5 & 3.4 & $-1 \cdot 7$ & $4 \cdot 3$ \\
\hline Total fat mass $(\mathrm{kg})$ & -0.5 & $2 \cdot 0$ & -1.0 & $2 \cdot 1$ & -0.9 & $2 \cdot 1$ & $-1 \cdot 1$ & $2 \cdot 3$ \\
\hline Total body fat percentage & -0.3 & 1.5 & -0.7 & 1.5 & -0.7 & 1.6 & -0.8 & $2 \cdot 0$ \\
\hline \multicolumn{9}{|l|}{ Completers } \\
\hline$n$ & \multicolumn{2}{|c|}{133} & \multicolumn{2}{|c|}{112} & \multicolumn{2}{|c|}{120} & \multicolumn{2}{|c|}{117} \\
\hline Weight (kg) & -0.8 & $2 \cdot 8$ & $-1 \cdot 8$ & 3.1 & $-1 \cdot 1$ & $2 \cdot 7$ & -1.8 & 3.3 \\
\hline BMI change $\left(\mathrm{kg} / \mathrm{m}^{2}\right)$ & -0.3 & 1.0 & -0.6 & $1 \cdot 1$ & -0.4 & 1.0 & -0.7 & $1 \cdot 2$ \\
\hline Waist circumference $(\mathrm{cm})$ & -1.3 & 3.7 & $-2 \cdot 7$ & 3.9 & $-1 \cdot 7$ & 3.6 & $-2 \cdot 1$ & 4.7 \\
\hline Total fat mass $(\mathrm{kg})$ & -0.5 & $2 \cdot 1$ & -1.4 & $2 \cdot 3$ & $-1 \cdot 1$ & $2 \cdot 2$ & -1.3 & $2 \cdot 8$ \\
\hline Total body fat percentage & -0.3 & 1.6 & -0.9 & 1.7 & -0.8 & 1.7 & -0.9 & $2 \cdot 2$ \\
\hline
\end{tabular}

OBLI, online basic lifestyle information; OBWM, online behavioural weight management; BEV, fortified diet beverage; BOCF, baseline observation carried forward.

${ }^{*}$ Only the primary outcome variables were imputed using the BOCF model. 
initial prescription. However, only two individuals met the criteria for daily use, so we combined the daily use with those using the website at least several (i.e. $>3$ ) times per week.

Fig. 2 illustrates changes in both weight $(\mathrm{kg})$ and fat mass (kg) based on website use among those in the OBWM groups. ANOVA for changes in both weight $(F=17.027$; $P<0.001)$ and fat mass $(F=14.869 ; P<0.001)$ were statistically significant. Post $h o c$ tests using Tukey's honestly significant difference revealed that the participants using the website several times per week lost significantly more weight and fat mass than those who accessed the OBWM website at least once per week, but less than several times per week, and those who used the website less than weekly ( $P<0.001$ for all contrasts). No other post boc contrasts were statistically significant; however, it should be noted that the participants using the OBWM website less than weekly ( $n$ 22) actually gained weight and fat mass.

Side effects. There were no primary side effects that occurred in $>5 \%$ of the total study sample except those listed in the 'other' category (other, $n 81$ or $14.1 \%$ of the total sample). The 'other' category was heterogeneous and no single condition was mentioned in more than three individuals per condition. When examining the side effects in each study intervention group, only flatulence/gas and those in the 'other' category occurred in $>5 \%$ of the OBLI + BEV group (nine of 139 participants or $6.5 \%$ for flatulence/ gas; twenty-five of 139 participants or $18.0 \%$ for other) and in the OBWM + BEV group (ten of 144 participants or $6.9 \%$ for flatulence/gas; twenty-two of 144 participants or $15.3 \%$ for other). The 'other' category was extremely heterogeneous and included reports of dizzy spells, burns, herniated discs, abdominal pain, allergies, backaches, broken fingers, bruises, cough, ear infection, knee pain and other conditions that were not likely to be caused by the study interventions. Few participants ( $n$ ) withdrew due to side effects (see Fig. 1 for details of attrition for each treatment group).

\section{Discussion}

The present study investigated the efficacy of a programme with a high potential for scalability. The programme applied an online behavioural modification programme with lowtouch support either with or without the additional support of a fortified diet cola beverage.

These results suggested that participants who used the online weight-loss programme (OBWM and OBWM + BEV) lost more weight than those in the online basic lifestyle condition (OBLI). No other contrasts were statistically significant. The secondary analysis revealed that among the participants in the OBWM condition, those who used the website most frequently experienced significantly more weight and fat mass loss. We hypothesised that the beverage also would result in weight loss and that there would be a synergistic effect between the OBWM programme and the study beverage, but this was not the case.

The weight losses found for the online intervention (OBWM) tested in the present trial were modest, but similar

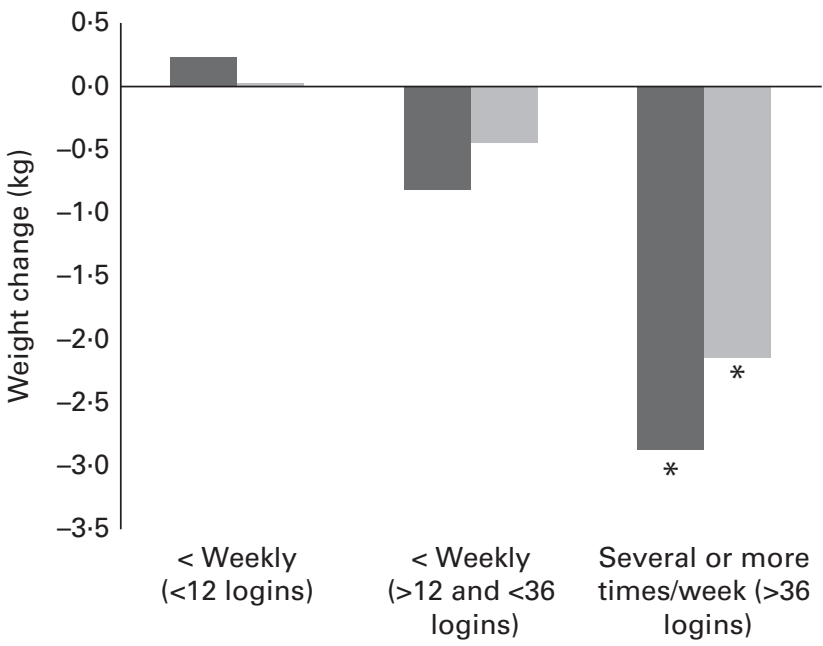

Categories of website use

Fig. 2. Weight $(\square)$ and fat mass $(\square)$ change (kg) by categories of weekly website use among the study completers. Only data obtained from those receiving some form of the online behavioural weight management programme were included. *Values were significantly different compared with those for participants using the website only weekly or less than weekly $(P<0.001$; post hoc test $)$

to those from some less-intensive published Web-based programmes ${ }^{(8,10,12)}$. For instance, in a trial conducted with military personnel, Hunter et al. ${ }^{(12)}$ reported a mean weight loss of $1.3 \mathrm{~kg}$ over a 6 -month treatment period. In an examination of eDiets.com (a commercial weight-loss programme over the Internet), Womble et $a l^{(8)}$ found a mean weight loss of $0.9 \%$ of initial body weight over 16 weeks.

Studies with longer treatment periods and a greater level of personal contact have found greater weight losses from Webbased interventions. For example, Tate et al. ${ }^{(5)}$ reported an average $4.1 \mathrm{~kg}$ weight loss after 6 months of an online weight-loss treatment. In a subsequent study, Tate et al. ${ }^{(6)}$ reported an average $4.4 \mathrm{~kg}$ weight loss after 1 year of intervention that included both an online treatment and email counselling. Gold et al. ${ }^{(35)}$ found that over 12 months, participants following an online, therapist-led programme (VTrim) lost more weight than a self-guided commercial online programme (eDiets.com) $(7 \cdot 8$ and $3.4 \mathrm{~kg}$, respectively). Future research should examine methods to increase weight loss, perhaps by increasing adherence to the online programme over a longer treatment period.

The present study had several limitations. First, there was low adherence to the initial prescriptions for OBWM website use (see Fig. 2) and beverage consumption (data not shown; only $28 \%$ of completers drank the recommended three cans per d). In addition, while we had participants' complete food diaries as a self-monitoring tool, we did not conduct standardised dietary assessments that would have been comparable between the US and UK sites that could have provided data on how the interventions influenced energy intake. Finally, we had differential attrition, both by group of assignment and by study site. It is not clear why dropouts were more frequent in the two OBWM groups or from the UK site; since 
study follow-up procedures were standardised across sites, there were no significant differences in treatment assignment by site and no substantial problems were reported for those in the OBWM groups. In addition, the only side-effect that occurred $>5 \%$ (flatulence/gas) occurred in the groups receiving the beverage, so problematic side effects would not explain the greater attrition in the OBWM groups. We posit that the burden imposed on the participants by the requirements of the self-led online programme may explain attrition in the OBWM groups.

The present study had a number of strengths including the very large sample size (when compared with most other previous studies), the relatively low overall attrition, the inclusion of the dual-energy X-ray absorptiometry-derived body composition assessment, the inclusion of participants from three sites that included a fairly large proportion of minorities (which increases the generalisability of the results), and the fact that the interventions were all of low intensity with regard to in-clinic personnel time and participant time, thus managing costs and increasing the likelihood that the programme could be easily deployed and used by most people.

\section{Acknowledgements}

The authors would like to acknowledge the research assistance of Hannah Lewis and Mariana Eberhard and the website managers Keith Keeney and Matt Parry. The authors would also like to thank the volunteers for their participation in the study.

The study was funded by The Coca-Cola Company. As an employee of the Coca-Cola Company, S. A. R was involved in the study origination and design, data interpretation and critical revision of the manuscript.

The authors' contributions are as follows: C. K. H. was involved in the study origination and design, data analysis and interpretation and critical revision of the manuscript; W. S. C. P. was involved in the study origination and design, data analysis and interpretation, and was chiefly responsible for the writing of the manuscript; C. L. was involved in conducting the study, data interpretation and critical revision of the manuscript; A. A. K. was involved in conducting the study and data interpretation; S. S. V. V. was involved in conducting the study, data interpretation and critical revision of the manuscript; G. D. F. was involved in the study origination and design, obtaining funding, conducting the study, data interpretation and critical revision of the manuscript; S. A. J. was involved in the study origination and design, obtaining funding, conducting the study, data interpretation and critical revision of the manuscript; C. M. was involved in conducting the study, data interpretation and critical revision of the manuscript; S. A. R. was involved in the study origination and design, data interpretation and critical revision of the manuscript; R. S. R. was involved in the study origination and design, conducting the study, data interpretation and critical revision of the manuscript; M. P. B. developed intervention materials and was involved in the conduct of the study; J. P. F. was involved in the study origination and design, obtaining funding, conducting the study, data interpretation and critical revision of the manuscript. All authors read and approved the final manuscript.

S. A. R. is an employee of The Coca-Cola Company. G. D. F. reported being a member of the scientific advisory board for Tate and Lyle. All authors agree that the present study was conducted in a manner consistent with the ILSI principles regarding conflicts of interest (see Rowe et al. ${ }^{(36)}$ ).

\section{References}

1. Finucane MM, Stevens GA, Cowan MJ, et al. (2011) National, regional, and global trends in body-mass index since 1980: systematic analysis of health examination surveys and epidemiological studies with 960 country-years and 9.1 million participants. Lancet 377, 557-567.

2. Flegal KM, Carroll MD, Odgen CL, et al. (2010) Prevalence and trends in obesity among US adults, 1999-2008. JAMA 303, 235-241.

3. Organisation for Economic Co-operation and Development (OECD) (2011) OECD health data 2010 - frequently requested data. http://www.oecd.org/document/16/03746en_2649_ 37407_2085200_1_1_1_3740700.html (accessed March 2011).

4. Bennett GG, Herring SJ, Puleo E, et al. (2010) Web-based weight loss in primary care: a randomized controlled trial. Obesity 18, 308-313.

5. Tate DF, Wing RR \& Winett RA (2001) Using Internet technology to deliver a behavioral weight loss program. JAMA $\mathbf{2 8 5}$, 1172-1177.

6. Tate DF, Jackvony EH \& Wing RR (2003) Effects of Internet behavioral counseling on weight loss in adults at risk for type 2 diabetes: a randomized trial. JAMA 289, 1833-1836.

7. Harvey-Berino J, Pintauro SJ \& Gold EC (2002) The feasibility of using Internet support for the maintenance weight loss. Behav Mod 26, 103-116.

8. Womble LG, Wadden TA, McGuckin BG, et al. (2004) A randomized controlled trial of a commercial Internet weight loss program. Obes Res 12, 1011-1018.

9. Williamson DA, Martin PD, White MA, et al. (2005) Efficacy of an Internet-based behavioral weight loss program for overweight adolescent African-American girls. Eat Weight Disord 10, 193-203.

10. Rothert K, Strecher VJ, Doyle LA, et al. (2006) Web-based weight management programs in an integrated health care setting: a randomized, controlled trial. Obesity 14, 266-272.

11. Micco N, Gold B, Buzzell P, et al. (2007) Minimal in-person support as an adjunct to Internet obesity treatment. Ann Behav Med 33, 49-56.

12. Hunter CM, Peterson AL, Alvarez LM, et al. (2008) Weight management using the Internet: a randomized controlled trial. Am J Prev Med 34, 119-126.

13. Wing RR, Tate DF, Gorin AA, et al. (2006) A self-regulation program for maintenance of weight loss. $N$ Engl $J$ Med 355, 1563-1571.

14. Arem H \& Irwin M (2011) A review of web-based weight loss interventions for adults. Obes Rev 12, e236-e243.

15. Hursel R, Viechtbauer W \& Westerterp-Plantenga MS (2009) The effects of green tea on weight loss and weight maintenance: a meta-analysis. Int J Obes 33, 956-961.

16. Hursel R, Viechtbauer W, Dulloo AG, et al. (2011) The effects of catechin rich teas and caffeine on energy expenditure and fat oxidation: a meta-analysis. Obes Rev 12, e573-e 581.

17. Dulloo AG, Duret C, Rohrer D, et al. (1999) Efficacy of a green tea extract rich in catechin polyphenols and caffeine in increasing 24-h energy expenditure and fat oxidation in humans. Am J Clin Nutr 70, 1040-1045. 
18. Rumpler W, Seale J, Clevidence B, et al. (2001) Oolong tea increases metabolic rate and fat oxidation in men. $J$ Nutr 131, 2848-2852.

19. Rudelle S, Ferruzzi MG, Cristiani I, et al. (2007) Effect of a thermogenic beverage on 24-hour energy metabolism in humans. Obesity 15, 349-355.

20. Belza A, Toubro S \& Astrup A (2009) The effect of caffeine, green tea, and tyrosine on thermogenesis and energy intake. Eur J Clin Nutr 63, 57-64.

21. Hase T, Komine Y, Meguro S, et al. (2001) Anti-obesity effects of tea catechins in humans. J Oleo Sci 50, 599-605.

22. Nagao T, Meguro S, Soga S, et al. (2001) Tea catechins suppress accumulation of body fat in humans. J Oleo Sci $\mathbf{5 0}$, $717-728$.

23. Westerterp-Plantenga MS, Jejeune MP \& Kovacs EM (2005) Body weight loss and weight maintenance in relation to habitual caffeine intake and green tea supplementation. Obes Res 13, 1195-1204.

24. Anderson JW, Baird P, Davis RH Jr, et al. (2009) Health benefits of dietary fiber. Nutr Rev 67, 188-205.

25. Smith CE \& Tucker KL (2011) Health benefits of cereal fibre: a review of clinical trials. Nutr Res Rev 24, 118-131.

26. Pasman W, Wils D, Saniez MH, et al. (2006) Long-term gastrointestinal tolerance of NUTRIOSE FB in healthy men. Eur J Clin Nutr 60, 1024-1034.

27. Guerin-Deremaux L, Li S, Pochat M, et al. (2011) Effects of NUTRIOSE $^{\circledR}$ dietary fiber supplementation on body weight, body composition, energy intake, and hunger in overweight men. Int J Food Sci Nutr 62, 628-635.
28. Guerin-Deremaux L, Pochat M, Reifer C, et al. (2011) The soluble fiber NUTRIOSE induces a dose-dependent beneficial impact on satiety over time in humans. Nutr Res $\mathbf{3 1}$, 665-672.

29. Mifflin MD, St Jeor ST, Hill LA, et al. (1990) A new predictive equation for resting energy expenditure in healthy individuals. Am J Clin Nutr 51, 241-247.

30. Nagao T, Komine Y, Soga S, et al. (2005) Ingestion of a tea rich in catechins leads to a reduction in body fat and malondialdehyde-modified LDL in men. Am J Clin Nutr 81, 122-129.

31. Pritchard JE, Nowson CA \& Wark JD (1997) A worksite program for overweight middle-aged men achieves lesser weight loss with exercise than with dietary change. $J \mathrm{Am}$ Diet Assoc 97, 37-42.

32. Altman DG (2009) Missing outcomes in randomized trials: addressing the dilemma. Open Med 3, 51-53.

33. Jebb SA, Ahern A, Olson AD, et al. (2011) Primary care referral to a commercial provider for weight loss treatment versus standard care: a randomised controlled trial. Lancet $\mathbf{3 7 8}$, $1485-1492$.

34. Ware JH (2003) Interpreting incomplete data in studies of diet and weight loss. N Engl J Med 348, 2136-2137.

35. Gold BC, Burke S, Pintauro S, et al. (2007) Weight loss on the web: a pilot study comparing a structured behavioral intervention to a commercial program. Obesity 15, 155-164.

36. Rowe S, Alexander N, Clydesdale FM, et al. (2009) Funding food science and nutrition research: financial conflicts and scientific integrity. Am J Clin Nutr 89, 1285-1291. 